\title{
Phylogenetic relationships in the genus Arachis based on seed protein profiles
}

\author{
A.K. Singh, Santosh Gurtu \& R. Jambunathan \\ International Crops Research Institute for the Semi-Arid Tropics (ICRISAT), Patancheru, A.P. 502.324 , India
}

Received S May 1993; accepted 30 December 1993

Key words: Arachis, electrophoretic bands, protein profile, homologies, percentage of similarity, phylogenetic relationships

\section{Summary}

Seed protein profiles of 19 accessions representing seven sections of the genus Arachis were studied using sodium dodecyl sulfate-polyacrylamide gel electrophoresis. The general profile showed appreciable homology between these taxa, supporting their classification based on morphology and cross-compatibility relationships. The accessions of section Arachis expressed a high variation confirming inferences from earlier studies. Variation between accessions of a species is limited. Accessions of the section Ambinervosae and Caulorhizae formed one cluster and accessions of sect. Erectoides and Procumbensae formed another. Whereas the representative accessions of sect. Triseminalae and Extranervosae formed two independent clusters. Using the percentage of dissimilarity in eiectrophoretic bands as a statistical genetic distance between accessions, sect. Arachis (containing the cultivated groundnut, A. hypogaea) is phylogenetically closest to sect. Erectoides followed by Procumbensae, Ambinervosae, Caulorhizae, Triseminalae and Extranervosae, respectively.

\section{Introduction}

Cross-incompatibility between species belonging to various sections of the genus Arachis has restricted the collection of evidence from cytogenetical analysis to draw phylogenetic relationships between them. Studies based on isozymes (Stalker et al., 1990), DNA restriction fragment length polymorphisms (RFLPs) (Kocher et al., 1991; Halward et al., 1991) and random amplified polymorphic DNA (RAPDs) (Halward et al., 1992) have been made, but seed protein profiles are still a powerful tool to ascertain genetic homology at the molecular level, and to resolve taxonomic and phylogenetic problems. They have recently been used successfully in sect. Arachis of the genus Arachis to confirm phylogenetic relationships based on cytogenetic investigations (Singh et al., 1991). The general profile in sect. Arachis showed considerable homology between the taxa despite ploidy differences. However. appreciable genetic differences exist between species

\footnotetext{
- Submitted as Joumal Article No. 1485 by the Intemational Crops Research Institute for the Semi-Arid Tropics (ICRISAT) Patancheru, A.P. 502 324, India.
}

which support the genomic subdivision and species limits based on a biosystematic definition of species. This study further indicated that seed protein profiles can be very useful at a macroevolutionary level in differentiating between species, but are of relatively lesser help at a microevolutionary level in differentiating between accessions of the same species. Therefore, the present study was undertaken as an extension of a previous study to explore the degree of genetic difference between species of different sections of genus Arachis at protein level, to elucidate phylogenetic relationships, and to identify marker proteins for each section/species, if possible.

\section{Materials and methods}

Details of seeds from taxa used in the present investigation have been summarized in Table 1 . 
Table I. Identity and taxonomic affinity of species/accessions used in the investigation

\begin{tabular}{|c|c|c|c|c|}
\hline \multirow{2}{*}{$\begin{array}{l}\text { S. } \\
\text { No. }\end{array}$} & \multirow{2}{*}{$\begin{array}{l}\text { ICG } \\
\text { No }\end{array}$} & \multirow[t]{2}{*}{ Identily } & \multicolumn{2}{|l|}{ Taxonomy } \\
\hline & & & Section & Series \\
\hline $\mathbf{I}$ & 8200 & $\begin{array}{l}\text { GKBPSSc 30067: PI } 468202 \\
\text { A. duranensis }\end{array}$ & Arachis & Annuae \\
\hline 2 & 8124 & $\begin{array}{l}\text { K 9484: P1 } 298639 \\
\text { A. batizocoi }\end{array}$ & Aruchis & Annuae \\
\hline 3 & 8210 & $\begin{array}{l}\text { GKBPSSc } 30081 ; \text { PI } 468327 \\
\text { A. batizocot }\end{array}$ & Arachis & Annuae \\
\hline 4 & 8144 & A. villosa (Coimbtore) & Arachis & Perennes \\
\hline 5 & 8216 & $\begin{array}{l}\text { GKP 10017: PI } 262141 \\
\text { A. rardenasii }\end{array}$ & Arachis & Perennes \\
\hline 6 & 8906 & $\begin{array}{l}\text { HLK 410; PI 338280 } \\
\text { A. stenosperma }\end{array}$ & Arachis & Perennes \\
\hline 7 & 8135 & $\begin{array}{l}\text { K } 7264 \text { : PI } 263393 \\
\text { A. monticola }\end{array}$ & Aruithis & Amphiploides \\
\hline 8 & 156 & $\begin{array}{l}\text { M 13: A. hypogaed } \\
\text { ssp. hyposued }\end{array}$ & Arachis & Amphiploides \\
\hline 9 & 221 & $\begin{array}{l}\text { TMV 2: A. hypogaea } \\
\text { ssp. fastigiata }\end{array}$ & Arachis & Amphiploides \\
\hline 10 & 13211 & 6676; A pusilla & Ambinervosae & - \\
\hline 11 & 13219 & 61100RFL: A. pusilla & Ambine rvosate & - \\
\hline 12 & 13222 & VSW 6791 WI FL; $A$. pinto & Caulorhizae & - \\
\hline 13 & 8973 & $\begin{array}{l}\text { GKPSc } 30134 ; \mathrm{PI} 468176 \\
\text { A. paraguariensis }\end{array}$ & Erectoides & Tertafoliolatae \\
\hline 14 & 8215 & GKPSC 30126. PI 468170 & Erectoides & Tertafoliolatae \\
\hline IS & 8945 & GK 30003: P1 468149 & Procumbensue & - \\
\hline 16 & 8904 & GKP 10034; A. rignoi & Procumbensue & - \\
\hline 17 & 11557 & KSSc $36(0) 8 \cdot 2 ; \mathrm{PI} 475986$ & Procumbensue & . \\
\hline 18 & 8131 & $\begin{array}{l}\text { GK 12922; PI } 338449 \\
\text { A triseminalis }\end{array}$ & Triseminalue & - \\
\hline 19 & 8142 & A. villosulicarpa (Coimbtore) & Extranervosae & - \\
\hline
\end{tabular}

Sodium dodecyl sulfate (SDS) - polyacrylamide gel electrophoresis

Protein profiles were resolved using SDS-polyacrylamide gel electrophoresis (Singh et al., 1991). However, since it was observed in the previous study that the general protein profiles have considerable homology in their major bands, and that most genetic differences were confined to minor bands, protein extraction was carried out on a defatted meal (100 mg) in $20 \mathrm{ml}$ of $2 \%$ SDS-buffer (pH 6.9) using Kinematica Polytron Homogenizer (Kinematica GmbH Kviens Luzean. Switzerland). The homogenates were centrifuged for 20 minutes at $3000 \times g$ and the extracts were filtered and electrophorized.
Variation in the position of bands was measured using Resolution factor value ( $\mathrm{Rf}$ value) as described earlier (Singh et al., 1991). Both minor and major bands were included in counting the number of bands, calculating percentage similarity and identifying unique bands which differentiate species belonging to different sections. Percentage similarity between pairs of accessions was calculated using Ladizinsky \& Hymowitz (1979) method. The species were clustered following Tocher's method (Rao, 1952), using percentage dissimilarity as the generalized statistical distance. In this method first species are arranged in onder of their relative distance from each other. Then two species/accessions having smallest distance are considered first, to which third species having smallest 


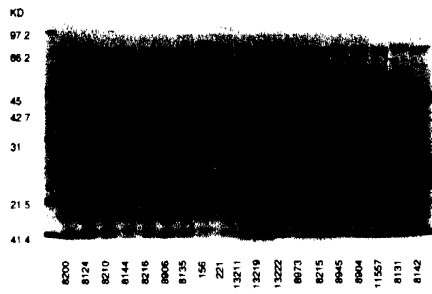

Fig. 1. Seed protein profiles of 19 accessions of Arachis species representing seven sections. Track 1 contains molecular weight of markers. Number below each track represents identity of genotypes as per Table 1 .

distance from first two species is added. Then fourth and so it goes on. When it is felt that addition of a particular species, results in an abrupt increase of average distance, this species is not included in that cluster and a second cluster is formed. This process is continued till all species are included in one or other cluster.

\section{Results}

The electrophoretic seed protein profiles of 19 species/accessions representing seven sections of the genus Arachis are presented in Fig. 1. Modification of the earlier electrophoretic technique resolved a greater number of bands (29) in these taxa. The maximum number of bands in any one taxon was 21 , recorded in A. pintoi belonging to sect. Caulorhizae, closely followed by the two accessions of sect. Ambinervosae (18) (Table 2). $R f$ value of these bands ranged from 0.14 to 0.96 , and they grouped almost identically across various accessions (Table 2). The accessions belonging to sect. Ambinervosae, Caulorhizae, Erectoides Procumbensae and Triseminalae, which are wild, have a greater number of fast-moving bands than do the accessions of Arachis and Extranervosae, which also have some cultivated accessions.

\section{Intra- and intersectional homologies}

Nine accessions belonging to sect. Arachis, including representatives of both $A$ and or $B$ genomes showed a similar number of bands. However, two accessions of
A. batizocoi carrying the B genome, expressed a comparatively lower degree of similarity (40.90-63.2\%) with other species of sect. Arachis (Table 3 ) and therefore, statistically formed a separate cluster as in previous studies (Singh \& Moss, 1982, 1984; Singh et al., 1991). Among the remaining species of sect. Arachis, the three tetraploid accessions, wild $A$. monticola and the two subspecies of cultivated $A$. hypogaea, resolved nearly identical number of bands with similar mobility, expressing 78-94\% of genetic homology. The four diploid species representing the A genome, also resolved many similar bands between them, with the percentage of similarity ranging from 58 to $88 \%$ (Table 3).

Among the other accessions representing the remaining six sections of genus Arachis, two accessions of $A$. pusilla (ICG 13211 and 13219) belonging to sect. Ambinervosae resolved identical number of bands with similar mobility and thereby $100 \%$ genetic homology (Table 3). Their homology with the species of sect. Arachis ranged from 32 to $50 \%$, while with the species belonging to five other sections it ranged from 42 to $56 \%$ (Table 3). They expressed highest genetic homology (56.0) with the A. pintoi (ICG 13222) of sect. Caulorhizae, (the three together formed a cluster) followed by $A$. triseminalis of sect. Triseminalae, $A$. villosulicarpa of sect. Extranervosae and accessions of sect. Procumbensae and Enectoides. The lone representative of sect. Caulorhizae, A. pintoi expressed a similar degree of homology with two accessions sect. Erectoides, A. sp. 30134 and A. sp. 30126 followed by the species of sect. Extranervosae, Triseminalae, and Procumbensae. The two accessions of sect. Erectoides and three of sect. Procumbensae resolved nearly equal number of bands with identical mobility. Their genetical homology based on the similarity of bands ranged from 65 to $93 \%$, they thereby formed a single cluster. Though the two accessions, GKPSC 30134 and GKPSC 30126 of sect. Erectoides have greater similarity between them than to three accessions belonging to sect. Procumbensae. The two representative accessions of sect. Triseminalae and Extranervosae stood distinct from rest of the species belonging to five other sections. They showed genetic homology ranging from 22 to $56 \%$ (Table 3). Section Triseminalae was closest to three accessions of sect. Procumbensae, $A$. rigonii, and $A$. sp. KSSC $36008-2$ and GK 30003 with genetic homology ranging from 53 to $56 \%$, followed by the accessions belonging to sect. Ambinervosae and Caulorhizae (Table 3). The accession from sect. Triseminalae was farthest in genetic homology 
Table 2. Distribution of denatured polypeptides of 19 species of genus Arachis representing seven sections

\begin{tabular}{|c|c|c|c|c|c|c|c|c|c|c|c|c|c|c|c|c|c|c|c|}
\hline \multirow[t]{2}{*}{ RF value } & \multicolumn{19}{|c|}{ A rachis species reprementing meven sectious of genus Arachis } \\
\hline & 1 & 2 & 3 & 4 & 5 & 6 & 7 & 8 & 9 & 10 & 11 & 12 & 13 & 14 & 15 & 16 & 17 & 18 & 19 \\
\hline 0.14 & + & + & + & + & + & + & + & + & + & + & + & + & + & + & + & + & + & + & + \\
\hline 0.22 & + & + & + & . & . & . & + & + & + & - & - & - & + & + & - & - & . & . & . \\
\hline 0.25 & + & + & + & + & + & + & + & + & + & . & . & . & + & + & + & + & + & . & . \\
\hline 0.29 & . & . & . & . &. & . & . & . & . & . & . & + & + & - & - & . & . & . & - \\
\hline 0.31 & + & . & + & . & . & + & + & + & + & + & + & + & . & . & . & . & . & - & . \\
\hline 0.33 & + & + & - & + & + & + & - & . & . & - & . & + & + & + & + & + & + & . & + \\
\hline 0.35 & + & - & . & + & + & + & + & + & + & + & + & + & + & + & + & + & + & + & + \\
\hline 0.37 & - & - & - & . & . & . & . & . & . & + & + & - & . & . & . & . & . & - & + \\
\hline 0.39 & + & + & + & + & + & + & + & + & + & + & + & + & + & + & + & + & + & + & + \\
\hline 0.41 & . & - & . & . & - & . & . & . & - & + & + & + & . & - & . & . & . & . & + \\
\hline 0,45 & + & . & . & + & + & + & + & + & + & + & + & + & . & . & . & . & . & + & + \\
\hline 0,49 & + & + & + & + & + & + & + & + & + & + & + & $\therefore$ & - & - & - & - & . & - & - \\
\hline 0.57 & . & + & + & - & . & - & . & . & . & . & . & . & - & . & - & . & + & . & . \\
\hline 0.59 & + & . & . & . & . & + & + & + & + & + & + & + & + & + & + & + & + & + & + \\
\hline 0.61 & . & + & + & . & . & - & . & . & . & + & + & . & - & - & . & . & . & + & . \\
\hline 0.65 & . & . & . & . & + & . & . & - & . & . & - & + & . & . & . & . & . & + & . \\
\hline 0.68 & + & . & . & + & . & + & . & . & . & $\cdot$ & - & + & . & + & . & - & . & - & + \\
\hline 0.71 & . & + & + & + & + & + & + & . & + & + & + & + & - & + & + & + & + & + & + \\
\hline 0.72 & + & . & - & . & - & . & - &. & . & & - & . & - & . & . & . & . & . & . \\
\hline 0.74 & . & + & + & + & + & + & + & + & + & + & + & + & + & + & + & + & + & - & - \\
\hline 0.76 & + & + & + & + & + & + & + & + & + & + & + & + & + & + & + & + & + & + & + \\
\hline 0.78 & . & + & + & . & . & . & . & . & . & + & + & + & + & + & + & + & + & - & . \\
\hline 0.81 & . & + & + & + & . & + & + & + & + & . & - & + & . & . & - & . & - & - & . \\
\hline 0.83 & + & " & . & - & + & . & + & + & + & + & + & + & + & + & . & . & - & . & . \\
\hline 0.84 & . & . & . & . & . & . & - & . & . & + & + & + & + & + & + & + & + & + & + \\
\hline 0.67 & . & . & . & . & . & . & - & - & . & + & + & . & . & . & + & + & + & + & . \\
\hline 0.90 & + & + & + & + & + & + & + & + & + & - & - & + & + & + & + & + & + & + & . \\
\hline 0.9 .3 & . & . & . & - & . & . & - &. & . & + & + & + & . & . & . & . & - & + & - \\
\hline 0.96 & + & + & + & + & + & + & + & + & . & . & . & + & + & + & . & + & + & + & + \\
\hline
\end{tabular}

Serial number of species as per Table 1 .

+ Denote present, - denote absent.

from the two accessions of $A$. batizocoi from sect. Arachis carrying the B genome. A. villosulicarpa of sect. Extranervosae, besides showing more than $50 \%$ homology with the accession of sect. Caulorhinae, also showed a similar degree of homology with $A$. triseminalis of sect. Triseminalae and to accessions of sect. Procumbensae, sect. Erectoides and species of sect. Arachis representing the A genome, such as $A$. villosa and $A$. stenosperma (Table 3 ). The variation between the protein profiles of accessions of the same species (A. pusilla, A. batizocoi, A. hypogaea) and between accessions of same series or section (Tetrafoliolatae and Procumbensae) was limited (Fig. I, Table 3).
The dendrogram (Fig. 2) drawn on percentage dissimilarity in bands and clustering using Tocher's method (using dissimilarity in bands as genetical distance between a pair of accessions) grouped the accessions into 6 clusters. Species of sect. Arachis, which contain cultivated $A$. hypogaea grouped into two clusters - one represented by the most diploid species, the wild tetraploid $A$. monticola and the two cultivars from two subspecies of $A$. hypogaea and the other by the two accessions of diploid $A$. batizocoi. The two accessions of $A$. pusilla from sect. Ambinervosae together with A. pintoi of sect. Caulorhizae formed third cluster. while the two accessions belonging to sect. Erectoides 


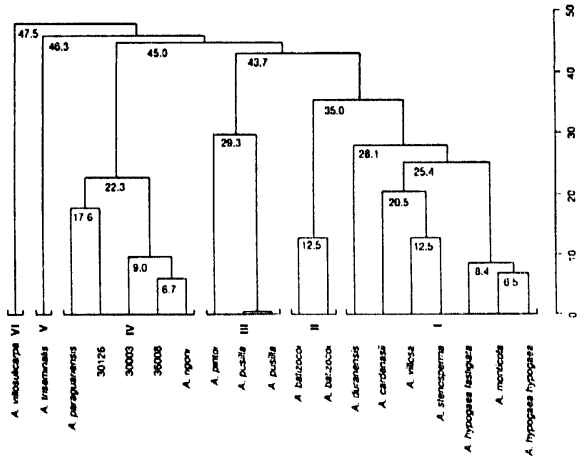

Fig. 2. Dendrogram and clusters constructed on the basis of percentage dissimilarities in the protein profiles.

and three accessions of sect. Procumbensae (earlier considered as a series of sect. Erectoides) formed the fourth cluster. The sole representatives sect. Triseminalae (monotypic) and Extranervosae formed fifth and sixth clusters (Fig. 2).

\section{Possible markers}

The protein profiles in genus Arachis are quite conservative, without substantial variations between the accessions belonging to different sections. This suggests a common ancestry of the accessions studied. The whole profile can be divided into three major regions classified by Cherry (1990): - region I of canarachin, region 2 of arachin of acidic subunits, and region 3 of arachin of basic subunits. The major variation representing genetic divergence between accessions is mostly confined to regions 2 and 3 of arachin. In sect. Arachis, the $\mathrm{B}$ genome species can be characterized by two typical marker bands at the $R f$ values of 0.57 and 0.61 of proteins of 29 and $29.5 \mathrm{KD}$. The A genome have bands similar to those of different sections, without any specific band typical to it, except that of $A$. dunanensis, which has an additional band at $\mathrm{Rf}$ value 0.72. The tetraploid accessions of sect. Arachis, both wild and cultivated, also do not have any specific typical marker band. The two accessions of sect. Ambinervosae have a typical band at the $R f$ values 0.37 and 0.41 ; the former is shared with the only accession of Extranenosae, A. villosulicarpa, and the latter with the sole accession of Caulorhizae, A. pintoi. The total profile picture of Ambinervosae and Caulorhizae is strikingly different from that of other sections. The sole member of Caulorhizae, A. pintoi has marker bands at $\mathrm{Rf}$ values 0.29 and 0.68 . It shares the former band with an accession A. sp. 30134 of Sect. Erectoides, and the latter with $A$. triseminalis of sect. Triseminalae. The five accessions belonging to sect. Erectoides and Procumbensae showed nearly identical profiles, with most bands similar to one or the other accessions of other sections, except for the one at $\operatorname{Rf}$ value 0.84 , which they shared with all other accessions, except those belonging to sect. Arachis. The lone accession representing sect. Triseminalae and Extranervosae has a different profile from the rest, and have a comparatively smaller number of bands. A. villosulicarpa has a typical major band at $\mathbf{R f}$ value 0.37 which it shares with two accessions of Ambinervosae, but with a quantitative (intensity) difference. Similarly, A. triseminalis of sect. Triseminalae has a typical band at an $\mathbf{R f}$ value 0.65 which it shares only with the lone accession of Caulorhizae. 
Table 3. Percentage of similarity among species belonging to different sections of genus Arachis

\begin{tabular}{|c|c|c|c|c|c|c|c|c|c|c|c|c|c|c|c|c|c|c|}
\hline & \multicolumn{18}{|c|}{ Arachis species reprementing seven sections of genus Arachis } \\
\hline & 2 & 3 & 4 & 5 & 6 & 7 & 8 & 9 & 10 & II & 12 & 13 & 14 & 15 & 16 & 17 & 18 & 19 \\
\hline $\mathbf{I}$ & 4() .9 & 40.9 & 57.9 & 61.1 & 68.4 & 68.4 & 72.2 & 63.2 & 36.0 & $36 .()$ & 480 & 55.0 & 60.0 & 38.1 & 42.9 & 40,9 & 36.4 & 45.0 \\
\hline 2 & & 87.5 & 61.1 & 55.6 & 55.0 & 55.0 & 50.0 & 50.0 & 320 & 32.0 & 38.5 & 50.0 & 55.0 & 47.4 & 52.6 & 57.9 & 31.8 & 27.3 \\
\hline 3 & & & 52.6 & 47.4 & 55.0 & 6.3 .2 & 579 & 579 & 37.5 & 37.5 & 38.5 & 42.9 & 47.6 & 40.0 & 45.0 & 50.0 & 318 & 21.7 \\
\hline 4 & & & & 80.0 & 87.5 & 66.7 & 61.1 & 61.1 & 33.3 & 333 & 52.2 & 45.0 & 57.9 & 50.0 & 55.6 & 52.6 & 40.0 & 50.0 \\
\hline 5 & & & & & 70.6 & 70.6 & 64.7 & 64.7 & 40.9 & 40.9 & 47.8 & 55.6 & 61.1 & 52.9 & 58.8 & 55.6 & 42.1 & 44.4 \\
\hline 6 & & & & & & 77.8 & 72.2 & 72.2 & 417 & 41.7 & 60.9 & 47.6 & 60.0 & 52.6 & 57.9 & 55.0 & 42.9 & 52.6 \\
\hline 7 & & & & & & & 93.8 & 93.8 & 478 & 47.8 & 54.2 & 550 & 600 & 45.0 & 50.0 & 47.6 & 42.9 & 38.1 \\
\hline 8 & & & & & & & & 87.5 & 43.5 & 43.5 & 50.0 & 57.9 & 550 & 400 & 45.0 & 42.9 & 381 & 33.3 \\
\hline 9 & & & & & & & & & 500 & 50.0 & 500 & 50.0 & 55.0 & 47.4 & 45.0 & 42.9 & 38.1 & 33.3 \\
\hline 10 & & & & & & & & & & 1000 & 56.0 & 37.5 & 41.7 & 47.6 & 45.5 & 43.5 & 52.4 & 47.6 \\
\hline 11 & & & & & & & & & & & 560 & 37.5 & 417 & 47.6 & 45.5 & 435 & 52.4 & 47.6 \\
\hline 12 & & & & & & & & & & & & 56.5 & 609 & 47.8 & 52.2 & 50.0 & 52.2 & 54.5 \\
\hline 1.3 & & & & & & & & & & & • & & 824 & 64.7 & 70.6 & 66.7 & 38.1 & 40.0 \\
\hline 14 & & & & & & & & & & & & & & 70.6 & 76.5 & 72.2 & 42.9 & 52.6 \\
\hline 15 & & & & & & & & & & & & & & & 92.9 & 86.7 & 50.0 & 44.4 \\
\hline 16 & & & & & & & & & & & & & & & & 93.3 & 55.6 & 500 \\
\hline 17 & & & & & & & & & & & & & & & & & 52.6 & 47.4 \\
\hline IA & & & & & & & & & & & & & & & & & & 50.0 \\
\hline
\end{tabular}

Serial number of species as per Tahle 1

\section{Discussion}

The protein profiles in the species/accessions representing seven different sections of genus Arachis broadly appear similar. corroborating earlier findings of conservative protein profile patterns in the genus Arachis (Klozova et al., 1983a, 1983b; Singh et al.. 1991). These differences and similarities observed support the broad sub-classification of genus Arachis proposed by Gregory et al. (1980) and Krapovickas (1990). Taking the percentage of dissimilarity in bands as a genetical distance between a pair of accessions. the total accessions studied grouped into six clusters (Fig. 2). The section Arachis, which contains cultivated tetraploid species, A. hypogaea (AABB) and several diploid species with A or B genomes (Table 1), clustered in two groups - one represented by tetraploid species having both $\mathrm{A}$ and $\mathrm{B}$ genomes and diploid species with the $A$ genome and the other by $A$. batizocoi with the B genome. These support our earlier findings (Singh et al., 1991). Species with the A genome show greater homology with accessions of other sections while accessions with the $B$ genome are farthest from them (Table 3).

The two accessions of Ambinervosae and an accession of Caulorhizae formed the other cluster, while the two accessions belonging to sect. Erectoides and three accessions of sect. Procumbensae (earlier considered a series of sect. Erectoides) formed another. The later grouping suggests that though the series Procumbensae has been raised to the status of section on the basis of morphological variation (Krapovickas, 1990), but at molecular level, it is still close to sect. Erectoides. The Ione representatives of sect. Triseminalae (monotypic) and Extranervosae. form two separate clusters.

Phylogenetically, based on relative genetic homology (similarity in bands), the closest to sect. Arachis (containing cultivated groundnut) are the accessions of sect. Erectoides, and Procumbensae followed by representatives of Caulorhizae and Ambinervosae. The two accessions belonging to sect. Triseminalae and Exrranervosae are the farthest (Table 3). These relationships support the earlier conclusions of Cherry (1975) based on electrophoretic protein and enzyme profile, and of Neucere \& Cherry (1975) and Klozova et al. (1983a, 1983b) based on immunochemical similarity. The accessions belonging to sections phylogenetically closer to section Arachis have greater prospects in genetic improvement of groundnut than distant ones.

The protein profiles of the accessions of the same species presented a very limited or no variation. This 
means that in certain cases protein profile may resolve the differences between accessions of the same species, while in other cases it may not. Probably it depends on degree of genetic divergence. For example, the two accessions of $A$. batizoco $i$ and that of $A$. hypogaea (representing two subspecies, not cultivars of subspecies) differ in major bands which can be used to differentiate accessions of these species, whereas the two accessions of $A$. pusilla did not show such differences even when they have different flower color (Fig. 1, Table 3). Nevertheless, the profiles as a whole, are unique to accessions belonging to different sections, and to species from different sections. Sect. Arachis has the maximum variability, as it contains maximum number of species (Krapovickas, 1990). It also appears to be highly evolved as it shows great variability in habitat (both perennial and annual), ploidy level (both diploid and tetraploid) and in chromosome morphology (Singh \& Moss, 1982, 1984). Therefore, these results corroborate earlier conclusions of Ladizinsky \& Hymowitz (1979) and highlight that protein profile can be used at macroevolutionary to delimit boundaries between sections and species. In addition the present study also indicates that in certain cases protein profiles can also differentiate between accessions of the same species at microevolutionary level, as is being reported for several genera (Crawford, 1990) and also for Arachis (Bianchi-Hall et al., 1993).

In conclusion the diversity in protein profiles can be utilized for identification, for classification and for tracing phylogenetic relationships between species, sections and accessions. Further, the protein profile has the advantage of representing full genome of a species unlike RFLPs and RAPDs, which represent a segment of DNA. This limitation sometimes may complicate the inferences, for example in RFLP studies, one probe/enzyme combination may implicate a set of species, while the other combinations may rule it out. Therefore, in broader perspectives phylogenetic relationship drawn on similarity between protein profile should be more direct and simple than molecular techniques such as RFLPs which need all possible probe/enzyme combinations and RAPDs a large number of primers to achieve conclusive phylogenetic inferences.

\section{References}

Bianchi-Hall. C.M., R.D. Keys, H.T. Stalker \& J.P. Murphy, 1993, Diversity of seed storage protein patterns in wild peanut (Arachis. Fahaceae) species. PI. Syst. Evol. 186: 1-15.

Cherry, J.P. 1975. Comparative studies of seed proteins and enzymes of species and collections of Arachis by gel electrophoresis. Peanut Sci. 2: 57-65.

Cherry, J.P., 1990, Peanut protein and product functionality. JACOS 67: 29.3-301.

Crawford, D.J. 1990. Plant Molecular Systematics. pp. 30-30 New York, Wiley.

Gregory, W.C. A. Krapovickas \& M.P. Gregory, 1980. Structure, varation, evolution and classification in Arachis. In: R.J. Summerfield \& A.H. Bunting (Eds). Advances in Legume Sciencek, pp. 469-481. Royal Botanic Gardens, Kew, England.

Halward, T.M., H.T. Stalker, E.A. La Rue \& G. Kochert, 1991. Genetic variation detectable with molecular markers among unadapted germplasm resources of cultivated peanut and related wild species. Genome 34: 1013-1020.

Halward. T.M., H.T. Stalker, E.A. Lo Rue \& G. Kocher, 1992. Use of single primer DNA amplifications in genetic studies of peanut (Arachis hypogaea L.). PI. Molec. Biol. 18: 315-320.

Klozova, E., J. Svachulova, J. Smart, E. Hadac, V. Turkova \& V. Hadacova. 198.3a. The comparison of seed protein pattem within the genus Arachis by polyacrylamide gel electrophoresis. Biol. Plant 25: 266-273.

KInzova, L., V. Turkova, J. Smart, K. Pitterova \& J. Svachulova, 198.3b. Immunochemical characterization of seed protein of some species of the genus Arachis L. Biol. Plan1 25: 201-208.

Kochen, G.D., T.M. Halward. W.D. Branch \& C.E. Simpson, 1991. RFLP variability in peanut (Arachis hypogaeu L.) cultivars and wild species. Theor. Appl. Genet. 81: 565-570.

Krapovickas. A., 1990. Classification of Arachis. In: IBPGR 1990 International Crop Network Series. 2. Report of workshop on genetic resources of wild Arachis species, held at CIAT, IBPGR, FAO, Rome, Italy.

Ladizinsky, G. \& T. Hymowitz., 1979. Seed protein electrophoresis in taxonomic and evolutionary studies. Theor. Appl. Genet. 54: $145-1.51$

Neucere, N.J. \& J.P. Cherry, 1975. An immunochemical survey of protein in species of Arachis. Peanut Sci. 2: 66-72.

Rav, C.R., 1952. Advanced statistical methods in biometric research. John Wiley \& Sons, New York.

Singh, A.K. \& J.P. Moss, 1982. Utilization of wild relatives in genetic improvement of Arachis hypogaea L. 2. Chromosome complements of species of section Arachis. Theor. Appl. Genet. 61: $305-314$.

Singh, A.K. \& J.P. Moss, 1984. Utilization of wild relatives in genetic improvement of Arachis hypogaea L. S. Genome analysis in section Arachis and its implications in gene transfer. Theor. Appl. Genet. 68: 355-364.

Singh, A.K., S. Sivaramakrishnan, M.H. Mengesha \& C.D. Ramajah, 1991. Phylogenetic relation in section Arachis based on seed protein profile. Theor, Appl. Genet. 82: 593-597.

Stalker, H.T., T.M. Jones \& J.P. Murphy, 1990. Isozyme variability among Arachis species. Amer. Peanut Res. Bduc. Soc. 22; 50 (abstr.). 